\title{
DETERMINANTS OF TUNISIAN CONSUMER PREFERENCES FOR FOREST HONEY: A MARKET SEGMENTATION ANALYSIS
}

\author{
Samir Ben Ali ${ }^{\mathrm{a}}$, Ibtissem Taghoutib, ${ }^{\mathbf{b} \mathbf{c}^{*}}$, Lamin Dalhoumi ${ }^{\mathrm{a}}$ \\ ${ }^{a}$ University of Carthage, Mograne Higher School of Agriculture (Tunisia, benali.samir17@gmail.com \\ ,lamindalhoumi58@gmail.com). ${ }^{b}$ University of Carthage, National Research Institute of Rural \\ Engineering,Waterand Forestry (Tunisia, ibtissem.taghouti@gmail.com). ${ }^{c}$ Centre de Recerca en Economia \\ i Desenvolupament Agroalimentari (CREDA-UPC-IRTA), Spain
}

\begin{abstract}
Forest honey is highly perceived by Tunisian consumers. However, its marketing potential is not explored in depth. Despite its relevance in the consumption habits in Tunisia, the literature on the consumer preferences toward this product is still very scarce. The aim of this paper is to study Tunisian consumers' preferences for forest honey and to identify market segments based on socioeconomic characteristics of consumers. The empirical analysis relies on a face-to-face questionnaire survey that was conducted in 2019 among Tunisian consumers. A sample of 200 respondents revealed that origin of honey and its floral type were the most important attributes. We identify three different groups of consumers using a two-step cluster method. The first segment of consumers (44\% of the sample) prefer eucalyptus and multifloral honey from the Northwest origin. The second group (39\%) is composed of consumers that tend to buy honey mainly produced in the eastern region of the country while the third one (17\%) describes consumers preferring thyme-rosemary' honey. The empirical model indicates that gender, income and grocery shopping task are the main determinants of the segment membership.
\end{abstract}

Key words: Forest honey, Consumer preferences, Tunisia, Cluster, Multinomial logit

Introduction .1

Tunisia is endowed with large natural forests and various suitable areas to honey production. Nevertheless, detailed information on honey production systems in forest areas and on Tunisian consumption preferences are still lacking. Despite the prominent position of honey production in Tunisia, beekeepers have not yet learned to understand the consumers' preferences and needs to reach their satisfaction and quality expectations. However, this sector contributes to local population livelihood in rural areas and forests. Currently, there are more than 12,000 beekeepers concentrated mainly in the western regions (Agricultural Extension \& Training Agency (AVFA), 2016). However, the majority of Tunisian beekeepers are nonprofessional "amateurs" with a limited number of 10 hives. With more than 265,000 hives, the average production per year is about 2,000 tons of honey (AVFA, 2016).

Mtimet et al. (2020) identified honey among the main organic products in Tunisia that need further attention to enhance its availability and access through the integration in mainstream sales channels which can reduce the gap between the purchase intention and actual purchase. However, Rached et al. (2012) highlighted the availability of organic food products in Tunisian markets is very limited and the share of organic products in the Tunisian food budget remains low representing less than $1 \%$. The beekeeping sector is facing various problems related mainly to market access and lack of beekeeping marketing skills. Meeting with different experts and stakeholders who are interested in promoting the honey sector in Tunisia stressed that the absence of forest honey in the Tunisian market channel is affecting the intention of purchase and reducing the product accessibility.

To our knowledge, the purchase intention of Tunisian consumers is very influenced by the affirmation of the quality of previous consumers. Despite the relevance of forest honey in supporting the livelihoods of local forest dependent communities and in Tunisian habits, there is no study that examined consumers' perception and demand for forest honey in this country. By doing so, our work contributes to the scarce literature on consumer behavior towards forest honey.

\section{Data collection and Methodology $\quad .2$}

The present study was conducted in Carrefour-La Marsa within the area of the capital of Tunisia. Data collection was carried out during the period from April to June 2019. Data were obtained from a face-toface survey on a sample of honey consumers. A random sample of 200 respondents were interviewed on preferred honey attributes. Data were analyzed by Two steps cluster analysis. Consumers preferences are related to their perception of product attributes, which describe the origin of honey, its floral type, flavor and color. These variables are measured on a 5-point Likert scale. The choice of the appropriate number of clusters was based on a minimum of Akaike information criterion (AIC). Table 1 describes the four underlying honey attributes, which determine consumer preferences. 
Table 1. Forest honey attributes

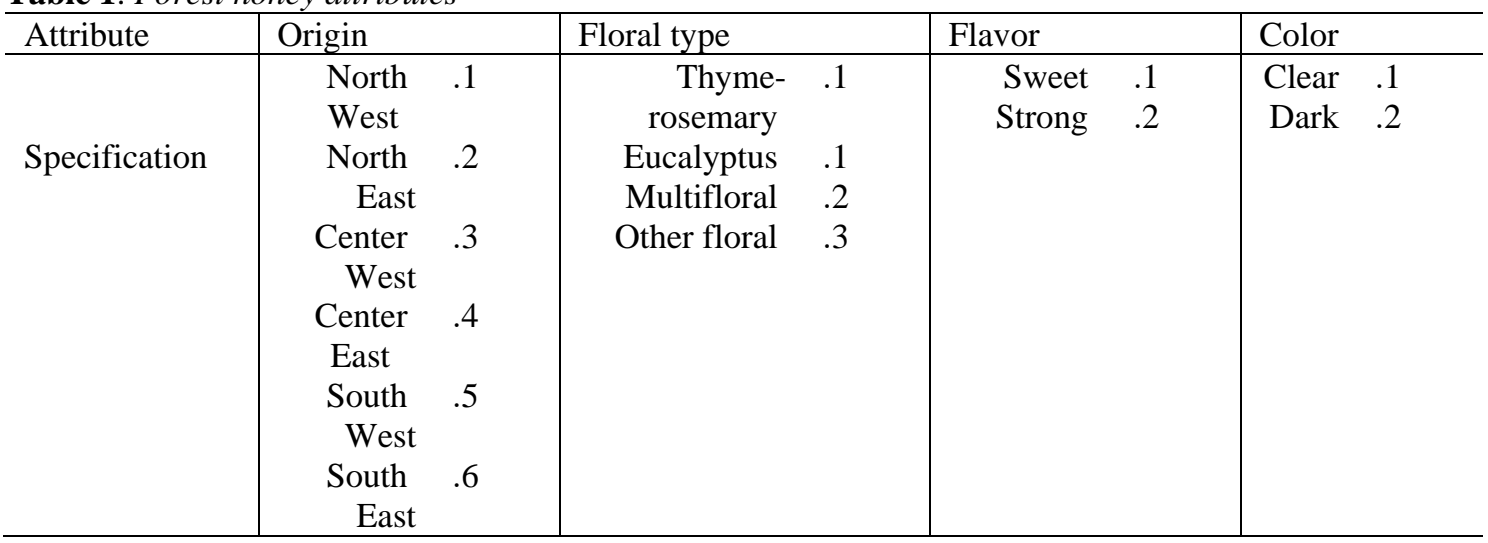

Source: Own elaboration

For the characterization of consumer segments, a multinomial logit analysis was used to assess the criteria influencing consumers' belonging to each market segment. These criteria have been approached by demographic and socio-economic variables which seem to be relevant for defining consumer opinion on aspects of preferred honey. In the multinomial logit analysis, the cluster variable was treated as the dependent variable and the demographic and socio-economic characteristics as independent variables. A multinomial logit analysis was used to assess the criteria influencing consumers' belonging to each market segment. By considering the variable $y_{i}$ which represents the membership cluster of consumer $i$, the model is written as:

$$
\text { Multinomial Logit } y_{\mathrm{i}}=\alpha+\beta_{\mathrm{j}} \mathrm{X}_{\mathrm{ij}}
$$

Where $\alpha$ is the intercept parameter; $\beta_{\mathrm{j}}=$ is the vector of slope parameter and $\mathrm{X}_{\mathrm{ij}}$ is the explanatory demographic and socioeconomic variables. These include gender, age, family member involved in honey, income level and Willingness to pay for forest honey (TND per $\mathrm{Kg}$ ).

Results .3

Three relatively homogeneous groups of honey consumers were identified based on the importance assigned to the Factors of honey preference (Table 2).

Table 2. Segmentation of consumer preference for forest honey

\begin{tabular}{|c|c|c|c|}
\hline Attribute & $\begin{array}{c}\text { Segment A } \\
\text { North West honey } \\
\text { consumers } \\
43.8 \% \\
\end{array}$ & $\begin{array}{c}\text { Segment B } \\
\text { Eastern regions honey } \\
\text { consumers } \\
38.9 \%\end{array}$ & $\begin{array}{c}\text { Segment C } \\
\text { Thyme-rosemary } \\
\text { honey consumers } \\
17.3 \%\end{array}$ \\
\hline $\begin{array}{l}\text { Honey origin } \\
\text { North West } \\
\text { North East } \\
\text { Center West } \\
\text { Center East } \\
\text { South West } \\
\text { South East } \\
\text { Floral type } \\
\text { Thyme-rosemary } \\
\text { Eucalyptus } \\
\text { Multifloral } \\
\text { Other floral } \\
\text { Flavor } \\
\text { Sweet } \\
\text { Strong } \\
\text { Color } \\
\text { Clear } \\
\text { Dark }\end{array}$ & $\begin{array}{l}100.0 \% \\
0.0 \% \\
0.0 \% \\
0.0 \% \\
0.0 \% \\
0.0 \% \\
0.0 \% \\
33.3 \% \\
66.7 \% \\
0.0 \% \\
42.9 \% \\
57.1 \% \\
42.9 \% \\
57.1 \%\end{array}$ & $\begin{array}{l}0.0 \% \\
42.9 \% \\
0.0 \% \\
57.1 \% \\
0.0 \% \\
0.0 \% \\
\\
53.6 \% \\
12.5 \% \\
0.0 \% \\
33.9 \% \\
\\
67.9 \% \\
32.1 \% \\
60.7 \% \\
39.3 \%\end{array}$ & $\begin{array}{l}20.0 \% \\
32.0 \% \\
40.0 \% \\
0.0 \% \\
4.0 \% \\
4.0 \% \\
100.0 \% \\
0.0 \% \\
0.0 \% \\
0.0 \% \\
0.0 \% \\
100.0 \% \\
0.0 \% \\
100.0 \%\end{array}$ \\
\hline
\end{tabular}

Source: Own elaboration

In addition, cluster analysis indicated that the origin and type of flowers were the main determinants factors that identify consumer clusters. Segment A (43.8\% of the total sample) is composed of consumers that prefer 'Northwest honey. Regarding the floral type, consumers of this group prefer multifloral honey and 
that of eucalyptus. Compared to the proportions of the entire sample, we can conclude that they do not pay much attention to flavor of honey nor its color. Segment B (38.9\%) includes 'Eastern regions' honey consumers. Their various floral type preferences indicate that they are interested by all type of honey that could be found in these regions. Compared with other segments, these consumers have more preference for sweet flavor and clear honey. Segment C (17.3\%) describes 'Thyme-rosemary honey consumers. They tend to buy honey characterized by strong flavor and dark color. The main origin of their purchases are Northern and Central Western regions of the country. Further details on the composition of the honey consumer' segments are presented in table 3 .

Table 3. Demographic and socio-economic characteristics of honey consumer segments

\begin{tabular}{l|l|l|l|l}
\hline Factor & Segment A & Segment B & Segment C & Overall sample \\
\hline Gender & & & & \\
Male & $49 \%$ & $46.4 \%$ & $68.0 \%$ & $48.6 \%$ \\
Female & $50.8 \%$ & $53.6 \%$ & $32.0 \%$ & $51.4 \%$ \\
Age & $3.2 \%$ & $8.9 \%$ & $12.0 \%$ & \\
$\leq 20$ & $44.4 \%$ & $57.1 \%$ & $36.0 \%$ & $45.1 \%$ \\
$21-35$ & $41.3 \%$ & $50.0 \%$ & $48.0 \%$ & $39.6 \%$ \\
$36-60$ & $11.1 \%$ & $7.1 \%$ & $4.0 \%$ & $8.3 \%$ \\
$>60$ & & & & \\
Income & $22.2 \%$ & $23.2 \%$ & $24 \%$ & $22.9 \%$ \\
$\leq 500$ & $60.3 \%$ & $69.6 \%$ & $36 \%$ & $59.7 \%$ \\
$501-1000$ & $12.7 \%$ & $7.1 \%$ & $40 \%$ & $15.3 \%$ \\
$1001-1500$ & $4.8 \%$ & $0.0 \%$ & $0.0 \%$ & $2.1 \%$ \\
$>1500$ & & & & \\
Home shopping & & & $28 \%$ & \\
Consumer & $27.0 \%$ & $78.6 \%$ & $72.0 \%$ & $75 \%$ \\
Other family member & $73.0 \%$ & &
\end{tabular}

\section{Source: Own elaboration}

Comparing the composition of each group with that of the overall sample makes it possible to identify the demographic and socio-economic characteristics of their members. Segment A can constitute a reference group. Any differences in the composition of the other two groups from this group may indicate a potential impact of certain demographic or socioeconomic factors on consumer preferences.

The most significant differences can be observed for segment $\mathrm{C}$. The predominance of men in this group and the relatively higher income level may explain the preference of thyme-rosemary honey. Indeed, thymerosemary honey, which is known by a strong flavor and a dark color, is more preferred by men. The relatively higher price of this honey makes it more accessible to categories having more willingness to pay. The composition of group B shows a higher female share indicating a greater preference for sweet flavor honey for consumers in this group. Moreover, the share of consumers who realize their shopping tasks is the lowest among three groups. These findings support the importance of demographic and socioeconomic variables in defining the preference towards honey aspects.

The MNL model results describe the potential effects of demographic and socioeconomic criteria on consumer preferences (table 4).

Table 4. Coefficient values of the multinomial logit model

\begin{tabular}{l|l|l}
\hline Variables & Segment B & Segment C \\
\hline Income & $-0.072(0.823)$ & $0.122(0.666)$ \\
Willingness to pay & $0.035(0.044)^{* * *}$ & $0.042(0.015)^{* *}$ \\
Age & $0.386(0.190)$ & $0.624(0.034)^{* *}$ \\
Gender & $0.850(0.049)^{* * *}$ & $-0.579(0.131)$ \\
Home shopping & $-0.293(0.586)$ & $-1.117(0.022)^{* *}$ \\
Constant & $-2.934(0.010)^{* * * *}$ & $-3.055(0.006)^{* * *}$ \\
\hline
\end{tabular}

Source: own elaboration

Results show that willingness to pay, age, gender and home shopping are significant and all variables have expected signs. However, the effect of income is not statistically significant for both segments. Empirical findings show a positive impact of "Willingness" for cluster B and C. Female consumers are more likely to belong to the group B than group C. Furthermore, our findings suggest that an increase in the consumers' age in segment $\mathrm{C}$ would increase the likelihood to buy honey produced from Thyme-rosemary plants with strong flavor and dark color compared to cluster A.

Shopping variable has a negative effect on the likelihood to be part of groups B and C rather than group A. Indeed, the purchasing criteria allows distinguishing between customers who actually consume honey and 
those who only buy the product. When buying honey, customers who do not consume honey may be more concerned about its availability and proximity service than its origin and type. Honey that satisfies the criteria of consumers in groups $\mathrm{B}$ and $\mathrm{C}$ is more likely to be accessible. It is worth noting that honey meeting the criteria for group A finds its origin only in the northwest zone. Thus, purchasing this type of product would require a special selection effort. A non-consumer will pay less importance to this selection.

Discussions and Conclusions $\quad .4$

Results indicate that origin of honey and its floral type are the main qualitative driver factors of customers' preferences. Three segments of consumers are identified. The first segment is composed of consumers that prefer honey produced in the Northwest region of the country. Honey preferences of this group are mainly driven by the origin of product. This product category can be attributed to the extension of forest area in this region allowing to predominate the beekeeping sector in Tunisia ( $80 \%$ of the total number of beehives are located in this region).

The second segment, which is mainly composed of women, tend to buy honey from eastern origin characterized by sweet flavor. In contrast, most of the members of the third cluster are men and perceive more honey based on thyme-rosemary plants. Indeed, compared to consumers of the first group, members of the latter two groups give more importance on the flavor of honey and its floral type rather than its origin. Furthermore, it is worth noting that consumers belonging to the segment $\mathrm{B}$ and $\mathrm{C}$ have higher willingness to pay than those of the first group do. Adequately product policy promoting attractive packaging and appropriate label information would target these two groups of consumers.

\section{REFERENCES}

Agricultural Extension \& Training Agency -AVFA (2016). Importance du secteur apicole. http://avfa.agrinet.tn/upload/supports_ar/importanceapicole.pdf

Mtimet, N., Souissi, A., \& Mhamdi, N. (2020). Tunisian consumers perception and behavior towards organic food products. New Medit: Mediterranean Journal of Economics, Agriculture and Environment= Revue Méditerranéenne d'Economie Agriculture et Environment, 19(1).

Rached, Z., Salmi, A., \& Khaldi, R. (2012). Technical performance of organic and conventional dates in Tunisia: the case of Hezoua region. New Medit, 11(3), 50-58. 